\title{
EEN UITWEG VOOR VERZINKEND SURINAME
}

DOOR

\section{VAN DRIMMELEN}

Dank zij een reeks prettig geschreven, zaakrijke artikelen, voorkomende in de Nw. Rott. Crt, van den bekenden reis-redacteur van dat blad, die onlangs een zevental weken in Suriname heeft doorgebracht, geniet het in Zuid-Amerika gelegen deel van Nederland, op 't oogenblik, hier te lande een belangstelling als wellicht nooit te voren.

Niet dat over deze kolonie anders niet wordt geschreven; integendeel, in de laatste jaren zelfs nog al veel, doch de daarover verschenen omvangrijke rapporten, uitgebracht door staatslieden en mannen van zaken van naam, kwamen uitteraard slechts in handen van weinigen, vereischen bovendien voor een grondige kennisneming nog al tijd en studie, maakten om die reden op het Nederlandsch publiek in het algemeen veel minder indruk dan bovengenoemde, in ruimen kring gelezen wordende, aantrekkelijke dagbladartikelen.

Maar ook deze belangstelling zal wel weer spoedig verflauwen, tenzij onder de velen die Suriname door eigen aanschouwing hebben leeren kennen en wat daarmede in den regel gelijkstaat, het ook hebben leeren liefhebben, er genoegzaam zijn te vinden om de lampen brandende te houden: de aandacht van kringen, die in koloniale vraagstukken belangstellen zullen blijven vragen voor ons schoon, echter zoo jammerlijk verwaarloosd Amerikaansch erfgoed.

$\mathrm{Nu}$ mag zeker niet worden verwacht, dat het Nederlandsch kapitaal zich daardoor zal laten vinden geld te steken in een land, waaraan reeds schatten zijn ten koste 
gelegd, zonder dat daarmede tot heden iets bevredigends is bereikt, maar als velen - der zake kundig natuurlijkduidelijk maken, waaraan het daar vooral hapert, aangeven op welke wijze dit aan hulpbronnen toch zoo rijke land tot ontwikkeling is te brengen, dan zou dit ten minste kunnen leiden tot het opmaken van een algemeen werkplan, tot het vaststellen der richting, waarin zijn sociale en economische ontwikkeling moet worden gezocht, en reeds dit zou voor de kolonie van onberekenbaar nut zijn.

Zulk een plan behoort natuurlijk rekening te houden met de lessen van het verleden en zoodanig te zijn, dat niet alleen de Nederlandsche Regeering maar ook de Surinaamsche bevolking er zich mede zal kunnen vereenigen, dus gaarne aan de verwezenlijking ervan zal willen medewerken.

$\mathrm{Nu}$ wil ik allerminst beweren, ten deze reeds den steen der wijzen te bezitten; alleen kan ik bogen op een veeljarige ondervinding in Suriname in verschillende verantwoordelijke betrekkingen en op een niet geringe kennis van land en volk aldaar, zoodat ik, zonder de grens der bescheidenheid te overschrijden, mij eenigermate bevoegd acht een oordeel uit te spreken over de meest vitale belangen van dit gewest.

Kortelijks zal ik daaromtrent hier een en ander in het midden brengen, in de hoop, dat bekwamer pennen dan de mijne, dit voorbeeld zullen volgen en niet zullen aflaten aan te dringen op het eindelijk toch eens opstellen van een "program van actie" voor de krachtige voortzetting van het beschavingswerk in Suriname, een halve eeuw geleden zoo goed ingezet met de vrijverklaring der slaven, het schenken van een Regeerings-Reglement op vrijzinnige grondslagen, de vervanging van het oudHollandsch recht door een behoorlijk beschreven wetgeving, een regeling voor den aanvoer van veld-arbeiders en nog meer, maar waarmede sedert is voortgegaan op een wijze, die de eer en den goeden naam van Nederland als koloniale mogendheid, althans in Amerika, niet heeft verhoogd. 
Suriname was altijd - is tot op zekere hoogte nog steeds - een typische plantage-kolonie, t.w. een agrarisch tropenland, dat geheel en al moest bestaan van één, hoogstens een paar uitvoerproducten. Mislukte de oogst of daalde de marktprijs in het land, ten bate waarvan die koloniën werden gemonopoliseerd, dan maakte de geheele bevolking er een crisis door van de soort, zooals Suriname die zoo dikwijls heeft doorstaan, inzinking medebrengend voor handel en landbouw, hongersnood soms voor de arbeiders-bevolking, want aan voortbrenging voor eigen gebruik werd uiterst weinig gedaan, als het begeerde uitvoerproduct er maar was.

Plantage-koloniën en vrijwel alle Amerikaansche koloniën konden eenmaal gerekend worden daartoe te behooren, waren meestal wel productieve landen, maar tot eenigszins bestendigen bloei, tot wezenlijk inwendige kracht, konden zij het nooit brengen. Een middenstand bestond er niet, kon uit de door een kapitalistisch bedrijf onmondig gehouden arbeidersstand ook niet voortkomen. Zij, die er tijdelijk het beleid van zaken in handen hadden, waren geen „home-seekers”, maar ambtenaren, militairen, vooral gelukzoekers, die er een campagne medemaakten om met het verdiende geld zoo spoedig mogelijk naar het moederland terug te keeren. De winsten werden uit die landen weggevoerd, binnenlandsch kapitaal kon er zich niet vormen. Alles stond in die landen een redelijke economische ontwikkeling in den weg, het volk bleef er arm.

Eerst toen die koloniën onafhankelijk werden of zelfbestuur kregen, de slavernij er plaats maakte voor vrijen arbeid, de nijverheid er haar intrede deed, de monocultuur er plaats maakte voor de polycultuur, vooral dit laatste, bleken die landen, door verkeerd Europeesch beleid zoo achterlijk gebleven, zeer ontvankelijk te zijn voor beschaving en welvaart, werden de meeste al spoedig een vruchtbaar veld voor Europeesche en NoordAmerikaansche ondernemingsgeest en geldbelegging.

Brazilië, dat eerst laat de slavernij afschafte en tot voor korten tijd vrijwel uitsluitend op koffie dreef, is een 
recent voorbeeld van de nadeelen, welke het één-voortbrengselstelsel steeds na zich sleept.

Haperde er iets aan den uitvoer van de koffie dan was algemeene malaise daarvan het onmiddellijk gevolg, de invoer verminderde en de staatsinkomsten ondergingen een gevoelige daling. In 1914, na het uitbreken van den oorlog, werd dit echter eensklaps anders. Brazilië begon toen ook rijst, katoen en boonen uit te voeren, benevens bevroren vleesch en ruw materiaal, zooals mangaanijzererts. De handelsbalans, welke maar zelden gunstige uitkomsten aanwees, kreeg toen een geheel ander aanzien. In 1914,1915 en 1916 wees die, ten bate van het land, een saldo aan van niet minder dan 800 millioen gulden. Zonder een veelzijdige voortbrenging en goed geregelden afzet was deze uitslag - zelfs in die buitengewone jaren nooit te bereiken geweest.

In Brazilië is gebleken, dat koffie den grond uitput, op den duur zoodanig verarmt, dat ontginning nog maar amper loont. De Regeering ziet in, dat er waakzaamheid noodig is, ten einde niet voor een catastrophe geplaatst te worden. De invoer van nieuwe cultures wordt er daarom aangemoedigd en een wetenschappelijk geleid proefstation verricht er proeven en doet er waarnemingen, ten bate van den landbouw in het algemeen.

Dit laatste behoort ook in Suriname te geschieden, ten minste veel meer en op grooter schaal dan zulks tot heden het geval is. Weliswaar is het economisch weerstandsvermogen der kolonie er in de laatste dertig jaren zeer op vooruitgegaan, dank zij het ontstaan van een talrijken kleinlandbouwerstand, welke voor de volksvoeding zorgt, ook van een paar z.g. bosch-industrieën, doch hare afhankelijkheid van de waarde van slechts een paar stapelproducten blijft desniettemin nog steeds zeer groot, zooals in de laatste twintig jaren weer zoo overtuigend is gebleken, toen, tengevolge van tegenslag met cacao en koffie, tijdperken van inzinking en financieelen nood elkaar haast op den voet volgden.

Wil de landbouwende kolonie Suriname ooit de economische bestendigheid erlangen, noodig voor haar volle 
sociale ontwikkeling, dan zal zij het voorbeeld moeten volgen van Brazilië en andere Zuid-Amerikaansche landen, die het invoeren van nieuwe cultures en moderne cultuur-wijzen krachtig bevorderen en er wel bij varen.

Voor dit doel zouden ambtenaren van het landbouwdepartement in Suriname, in de omringende landen economische ontdekkingstochten moeten ondernemen, ten einde in loco te onderzoeken, wat daar den vooruitgang bevordert en waaraan het is toe te schrijven, dat die landen de kolonie in economisch opzicht zoo ver achter zich laten. Op hier bedoelde wijze zou van reeds elders verkregen resultaten voor de kolonie partij te trekken zijn.

$\mathrm{Nu}$ zou het ondankbaar zijn en onvolledig hier niet te vermelden, dat het invoeren van nieuwe cultures in de laatste jaren bij herhaling is beproefd, zelfs met geldelijken steun van het Koloniaal Gouvernement. De heveaen de bananen-cultuur voor uitvoer zijn er op groote schaal ondernomen maar wegens ziekte in het gewas weer opgegeven. Wij vragen ons echter af, of deze ondernemingen, met hun vèrstrekkende economische gevolgen, niet met te groote overhaasting zijn begonnen? Bestond er van meet af aan wel de minste zekerheid, dat deze cultures zouden gelukken? wij gelooven van niet.

In elk geval valt uit het gebeurde de leering te putten, dat aan de invoering van cultures, waaromtrent nog geen plaatselijke ondervinding bestaat, proefnemingen behooren vooraf te gaan, waaruit kan blijken, dat die cultures voldoende loonend zullen zijn. Staat dit eenmaal vast, eerst dan worde overwogen of het koloniaal Bestuur de invoering daarvan behoort te bevorderen door aanmoediging van het particulier initiatief.

Een kort woord over de volksgroepen in Suriname, wier belangen naast de aloude plantage-belangen, daar steeds meer op den voorgrond treden.

Het is een eenigszins zonderlinge samenleving de Surinaamsche. $Z$ ij vertoont nog veel gelijkenis met die der middeleeuwen. Bovenaan een paar duizend blanken en een eenigszins grooter aantal personen van gemengd 
ras, de meer ontwikkelde, de burgerlijke, kapitalistische elementen, overigens de volksmassa, meerendeels sociaal en politiek onmondige en nooddruftige menschen van verschillenden tropischen landaard.

$\mathrm{Bij} 80 \%$ der Surinaamsche bevolking, kan men zeggen, staat de armoe op stal. Als voorzitter eener kolonisatiecommissie beschikteik in 1910 over gegevens, waaruit viel af te leiden, dat ruim $60 \%$ der bevolking moest leven van minder dan 25 cent daags en de helft hiervan van wellicht nog minder dan 15 cent.

Het geldloon der op de plantages werkende immigranten bedroeg tot $1921^{1}$ ), omgeslagen over het geheele jaar, voor mannen nooit meer dan gemiddeld 35 cent, voor vrouwen niet eens 20 cent daags. Gouddelvers en balata-arbeiders, die gerekend worden te behooren tot de goedbetaalde arbeiders, verdienen gewoonlijk niet meer dan $f 300$ en $f 400$. 's jaars, ambachtslieden, kleinlandbouwers, klein-handelaars en dergelijken brengen het maar zelden tot $f 500$, het laagst belastbaar inkomen.

In 1919 hadden op een bevolking van 114 duizend zielen slechts 2200 een inkomen van $f 600$ en daarboven, kwamen op de kiezerslijst niet meer dan 674 kiezers voor, dat zijn lieden met een inkomen van $f 1400$ en meer's jaars.

Uit het vorenstaande blijkt, hoe weinig welvaart er in Suriname bestaat, hoe armoedig de volksmassa er nog is.

Tot betere beoordeeling van den geschetsten toestand zij hier nog medegedeeld, dat de meeste artikelen voor dagelijksch gebruik, omdat zij ingevoerd moeten worden, er duur zijn, veel duurder b.v. dan in Nederland.

$\mathrm{Nu}$ heeft in warme landen, waar het klimaat geringe eischen stelt aan kleeding en huisvesting, armoede niet het deerniswekkend karakter van die in noordelijker streken, maar ook in de tropen missen de weinig bedeelden veel levensgenot, vooral de middelen om zich uit hun primitieven staat op te heffen, is hun hulpeloosheid op zoo velerlei gebied dikwijls oorzaak, dat zij der maatschappij meer tot na- dan tot voordeel strekken.

$\left.{ }^{1}\right)$ Einde 1920 is het loon der gecontracteerde plantage-arbeiders vrij aanzienlijk verhoogd. 
Opheffing uit dien vrijwel chronischen staat van armoede zou in Suriname, waar zeer veel voor een hoogeren levensstandaard vatbare elementen zijn, de opkomst beteekenen van een derden stand, van de bevolkingsgroep welke op den duur het meest kan bijdragen tot de sociale en economische ontwikkeling der kolonie.

Konden , om eens een voorbeeld te noemen, de thans zoo uiterst geringe inkomsten der bevolking met 30 cent per hoofd en per dag worden vermeerderd, wat geenszins onmogelijk lijkt, dan zou dit voor de koloniale gemeenschap een meerdere koopkracht van omtrent 13 millioen gulden 's jaars beteekenen.

Met deze vermeerdering van het jaarlijksch, maatschappelijk inkomen zou veel, wat nu te wenschen overlaat, anders worden. Het volk zou zich beter voeden, kleeden en huisvesten, er zou meer vertier, minder werkloosheid zijn en de prikkel van voldoend beloonden arbeid zou ongetwijfeld tot meer inspanning, tot grooter productiviteit leiden; de koloniale middelen zouden er zoodanig door worden versterkt, dat de kolonie voor hare eng huishoudelijke uitgaven de moederlandsche subsidie wellicht al spoedig zou kunnen ontberen.

Met dit voorbeeld willen wij alleen duidelijk maken, dat het welvaren der kolonie veel meer afhangt van de econonomische kracht der individuen dan van de getalsterkte harer bevolking.

Maar ook het gehalte is ten deze een belangrijke factor en daarom willen wij er hier nog eens op wijzen, dat een aanwas der bevolking in hoofdzaak met weinig ontwikkelde, voor het kolonisatiewerk minder geschikte immigranten, zooals thans plaats vindt, die bevolking niet veredelt, integendeel vergrooft, de oplossing van het vraagstuk harer verheffing tot een hooger peil dan waarop zij nu staat, niet vergemakkelijkt.

Koloniale vraagstukken, hoe lastig ook, zijn evenwel voor oplossing vatbaar, zooals de Vereenigde Staten op Cuba hebben aangetoond.

Onmiddellijk na de verovering van dat doordeschuld van Spanje zoo achterlijk en arm gebleven land, hebbendeAme- 
rikanen daar op haast elk gebied hervormingen ingevoerd.

De gele koorts, welke er van 1760 onafgebroken had geheerscht, werd in tijd van twee jaar geheel uitgeroeid; het sterftecijfer in 1898 ruim $93 \%$ binnen vier jaren teruggebracht tot $20 \%$. Malaria en tuberculose werden er met goeden uitslag bestreden, zoodat Havanna al spoedig een der gezondste steden van Amerika werd.

Het belastingstelsel werd herzien, hooger eischen aan ambtenaren gesteld, de suikerindustrie en immigratie aangemoedigd, cultuur-methoden verbeterd.

Alleen reeds in 1900 werden duizend onderwijzers naar Harvard gezonden om hun onderwijs-methode te verbeteren. Een andere pedagogiek, beschavingswerk op velerlei gebied veranderden er in korten tijd de politieke en sociale inzichten.

In vier jaren tijds werd het uitgeputte eiland hervormd tot een welvarend land, een welvaart welke zich niet beperkte tot enkele bevoorrechte standen, doch waarin de geheele bevolking ruimschoots deelde. (Zie: Memoirs of Gemera' W'od)!

De Vereenigde Staten hebben op Cuba aangetoond, dat er middelen bestaan om achterlijke, tropische landen in een waarneembaar snel tempo, in bevredigende mate economisch sterk te maken.

Zulke middelen zijn natuurlijk ook voor Suriname aan te wijzen, waar de gang van zaken, vooral in de laatste jaren, snel naar beneden voert en waar krachtige pogingen in het werk moeten worden gesteld om algeheel verval en nationale schande te voorkomen.

Een der deugdelijkste middelen, naar het schijnt, deugdelijk omdat vele Amerikaansche landen het reeds met den besten uitslag hebben beproefd, is de invoering van nieuwe culturen, geschikt voor den grooten, veelal uitheemschen, zoowel als voor den kleinen of inheemschen landbouw en waarvoor bodem, klimaat en geografische ligging zich bijzonder eigenen.

Vooral de kleine landbouw, waarin ruim $40 \%$ der bevolking een bestaan vindt en welke tot heden veel te weinig een bevredigend bestaan oplevert, heeft behoefte aan 
een of meer snel rijpende gewassen, waarvoor ook goede afzet in het buitenland is te vinden. Nu werkt deze over't algemeen nijvere bevolkingsgroep - verreweg de talrijkste - voor een meestal verzadigde markt, mist daardoor den prikkel tot groote productiviteit. Kon zij zich toeleggen op den verbouw van loonende producten als hooger bedoeld, de voornaamste oorzaak van geringen welstand en werkslapte ware daarmede weggenomen en het aantal personen, die bijdragen in de direkte belastingen, zou zich spoedig verveelvoudigen.

Wat van het volksbedrijf ten deze te verwachten is, bleek gedurende de oorlogsjaren, toen een gretige markt van nog al eens bij de pakken neerzittende landbouwers, ijverige bewerkers van den bodem maakte en nooit gekende welvaart onder hen verspreidde. De levendigheid in dit bedrijf verflauwde echter weer, toen de prijzen der voedingsmiddelen voor binnenlandsch gebruik geen behoorlijke winst meer beloofden.

Voor het invoeren van nieuwe cultures komt allereerst de bananenteelt voor uitvoer in aanmerking, welke in de laatste twintig jaren voor vele Midden-Amerikaansche landen van zoo groote economische beteekenis is geworden en waarvoor klimaat, bodem en ligging van Suriname zich goed eigenen.

De banaan, waarvan een verwante soort eeuwenlang het hoofdvoedsel in tropisch Amerikaansche landen is geweest, had aan het einde der vorige eeuw nog geen wereldbeteekenis, zooals koren, rijst en bevroren vleesch, doch heeft die gekregen, toen wakkere pioniers het vervoer over groote afstanden uitdachten van die aan spoedig bederf onderhevige vruchtsoort. De uitbreiding welke de cultuur daardoor onderging was verbazingwekkend en het vervoer der vruchten naar Noord-Amerika en naar Europa nam fabelachtig snel toe.

Vooral de Midden-Amerikaansche staten zijn in die cultuur sterk betrokken en beschikken voor dit doel over een talrijke vloot snelvarende transportschepen, welke grootendeels op New-Orleans varen. 
De handel in en het transport van het hierbedoelde tropische voortbrengsel zijn op uitstekende wijze georganiseerd en was van meet af aan in handen van de United Fruit Company te Boston, welk lichaam daardoor den staat van een trust heeft gekregen.

De U. F. C. koopt en vervoert niet alleen, op een schaal, welke alleen te vergelijken is met die van den uitvoer van bevroren vleesch uit Zuid-Amerika, maar legt zelve ook groote plantages aan en waar noodig, voor het vervoer naar de kust, spoorwegen.

De oostkust van Midden-Amerika trekt op die wijze groote voordeelen uit de bananen-cultuur en de trustpolitiek welke de U. F. C. voert, wettigt het vermoeden, dat zij nog steeds bereid zal worden gevonden hare belangen onbeperkt uit te breiden.

Voor de planters heeft deze staat van zaken het nadeel, dat de U. F. C. de prijzen der producten vaststelt, maar tot heden maken beide betrokken partijen blijkbaar zeer goede zaken. De cultuur toch breidt zich nog voortdurend uit, vooral in Costa Rica, Panama, Honduras, Guatemala, Nicaragua en Columbia en die met dit deel van Amerika eenigermate bekend is, weet, dat zonder de U. F. C. de planters aldaar wellicht geen bananen zouden verbouwen en de handelsbalans dier landen geenszins het gunstig beeld zou vertoonen van thans.

Ziekte in den aanplant - niet alleen de in Suriname bekende Panama-ziekte, doch ook de Congo-ziekte treedt in de meeste dier landen op, doch de U. F. C. hoopt die meester te worden.

Zooals gezegd, de U. F. C. verscheept ook naar Europa en naar het zich laat verluiden, hebben alle met haar in concurrentie tredende Europeesche transport-maatschappijen zich vroeger of later, uit zelfbehoud, steeds onder haar toezicht moeten stellen. Hoe dit ook zij, op hare groote ,efficiency”, wat aangaat handel en transport, mocht hier wel eens de aandacht worden gevestigd.

$\mathrm{Nu}$ in Suriname pogingen worden aangewend om de in 1910 opgegeven bananen-cultuur opnieuw aan te vatten, verdient het ongetwijfeld aanbeveling de oude betrek- 
kingen met de U. F. C. weer aan te knoopen, zich van hare machtige medewerking te verzekeren ${ }^{1}$ ).

Wil die cultuur loonend en van beduidend economische beteekenis zijn, dan behoort zij — na afloop van geslaagde proefnemingen - op groote schaal te worden ondernomen. Als niet eens per week wordt verscheept en dit reeds vereischt een beplante oppervlakte als bij den opzet in 1908 werd vastgesteld, nl. van 3000 H.A., dan gaat er van het product, dat het geheele jaar door aanrijpt, door te vroeg of te laat oogsten, veel verloren, wordt de kans op winst daardoor zeer gering. Voor de bananenteelt en den afzet daarvan wordt derhalve een organisatie en een kapitaal vereischt, waarover tot nu toe alleen de U. F. C. kon beschikken en het komt geraden voor daarmede rekening te houden, wanneer in Nederland plannen worden ontworpen om Suriname tot een tropisch fruit uitvoerend land te maken.

Door de aan hoofde dezes bedoelde schrijvers over Suriname zijn reeds tal van goed inzicht en kennis van zaken getuigende middelen aan de hand gedaan, waarvan vele, mits beleidvol toegepast, ongetwijfeld zullen leiden tot opheffing van misstanden en bevordering van den algemeenen welstand, zoodat mijn beschouwingen daaromtrent hier gevoegelijk achterwege kunnen blijven. Over één onderwerp echter wensch ik iets in het midden te brengen en dit betreft de spreekwoordelijk geworden rijkdommen van het land.

In de eerste plaats dan over de geschiktheid van den bodem voor cultures.

De woorden vruchtbare kuststreek liggen in Suriname als 't ware op de lippen bestorven. Schuilt hierin geen overdrijving?

In de door de samenwerking van zee en rivieren gevormde kuststreek ligt veel vruchtbaar land, maar ook veel dat

1) In de Memorie van Antwoord op het Voorloopig Verslag der Koloniale Staten, betreffende de begrooting voor 1924, deelt de Gouverneur mede dat - naar aanleiding van het bezoek van Dr. Stahel aan Costarica - de hoofdleider der United Fruit Company aldaar heeft toegezegd naar Suriname te zullen komen, uit welk bezoek te zijner tijd wellicht waardevolle connecties voor de kolonie kunnen voortkomen. 
voor den landbouw niets aantrekkelijks heeft. In dit verband noem ik slechts de terreinen zich uitstrekkende zuidwaarts van de hoofdstad, het Paradistrict en de oevers der Wayombo. Toen een vijftiental jaren geleden de U. F. C. naar een complex landerijen zocht, geschikt voor den aanplant op groote schaal van bananen, bleek zulk een terrein niet te vinden. De ten opzichte der hoofdstad gunstig gelegen, voor cultuur geschikte, woeste gronden waren in vroeger eeuwen alle uitgegeven aan personen, wier namen in het domein-archief zelfs niet meer bekend staan of wier nakomelingen het recht daarop reeds lang hebben prijsgegeven, in elk geval er geen gebruik meer van hebben. Toch worden hun eigendomsrechten nog steeds geëerbiedigd en er bestaat geen wettelijke regeling om dergelijke verwaarloosde eigendommen weer in den boezem van het domein te doen terugkeeren. In het z.g. oude deelder kolonie kon de U.F.C. dus niet klaarkomen, terwijl het aan de Coppename en Wayombo aangeboden domeinland voor het beoogde doel ongeschikt bleek te zijn.

Intusschen is het haast niet denkbaar, dat in een land, woest en ledig nog grootendeels, geen complex te vinden zou zijn geschikt voor den aanleg van een groote landbouw- onderneming, doch het Koloniaal Bestuur kon daaromtrent niet de minste aanwijzing doen.

Krasse onwetendheid van dat Bestuur, wat betreft het voorkomen van voor den aanplant van stapelgewassen geschikt domeinland, is toen oorzaak geweest, dat een der kapitaal-krachtigste handelslichamen in de Vereenigde-Staten ervan moest afzien om in Suriname een groote landbouw-onderneming op touw te zetten.

Plannen om aan die ongelukkige toestanden op domaniaal gebied een einde te maken, bestaan reeds lang, de verwezenlijking daarvan laat echter - als zooveel daarginds - weer eindeloos op zich wachten.

Hetgeen omtrent de kuststreek is gezegd, geldt in nog sterker mate voor de meer landwaarts in gelegen bosschen. Dat deze vele waardevolle houtsoorten bevatten is voldoende aangetoond, maar over het voorkomen daar- 
van, over den houtrijkdom per vlakte-eenheid is nagenoeg niets bekend.

Als b.v. de directie van het Panama-kanaal aan Suriname de levering wilde opdragen van een paar duizend kubieke meter eener daar voorkomende, tegen den aanval van paalwormen bestand gebleken houtsoort, zou het die bestelling niet op zich kunnen nemen, aangezien er niet de minste zekerheid bestaat, wat aangaat de houtmassa per hectare van die verspreid groeiende houtsoort.

Daaromtrent tast men nog geheel in het duister en houtkap zonder tijdroovend, deskundig vooronderzoek, in wouden met gemengde vegetatie, is een bedrijf, waaraan veel risico is verbonden.

Een stelselmatig onderzoek naar den rijkdom van voor uitvoer geschikt hout, op gemakkelijk te bereiken perceelen, zou aan die onzekerheid een einde maken, de particuliere ondernemingsgeest ongetwijfeld aanwakkeren, welke zeker bereid zal worden gevonden, boven en behalve de gewone retributie, voor de op die wijze verkregen bedrijfszekerheid te betalen.

Tot welk een niet te verdedigen grond-politiek volslagen onbekendheid met de hulpbronnen van het land soms leidt, blijkt uit het navolgende.

Een paar jaar geleden werd van een nieuw opgerichte Nederlandsche houtkap-maatschappij, met voldoend kapitaal, voor den tijd van 10 jaren en geheel kosteloos, vergunning verleend om op een terrein, groot niet minder dan 1 millioen hectaren, een onderzoek in te stellen naar ontginbare bosch-perceelen, met toezegging dat haar die in concessie zouden worden afgestaan. Over de uitgifte van een dergelijke logge massa land, nog wel in dat gedeelte der kolonie, door zijn vele bruikbare waterwegen als 't ware aangewezen voor bosch-ontginning, waren de houtkappers en houtopkoopers in Suriname slecht te spreken, omdat zij daarin, zeer terecht, voor langen tijd een belemmering zagen voor de uitbreiding van het inheemsch bedrijf.

Toch viel voor die opzienbarende wijze van uitgifte van domeinbezit nog wel iets te zeggen. Immers het was het eenige middel om aan de maatschappij, welke groote uit- 
gaven had te doen voor onderzoek en voorbereiding, voldoenden waarborg te geven, dat zij tenslotte de hand zou kunnen leggen op een genoegzaam aantal ontginbare boschperceelen.

Het behoeft natuurlijk geen betoog, dat de uitgifte van een zoo enorme uitgestrektheid bosch in één hand, vermoedelijk schatten bevattend, waarvan de waarde niet kan worden begroot, ongewenscht is.

Over den mineralen rijkdom der kolonie en of zij in hare boven-rivieren wellicht een waterkracht bezit, welke omgezet in electrische bedrijfskracht, ten deele althans, het gemis aan steenkolen zou kunnen vergoeden, dezelfde onzekerheid, dezelfde onwetendheid en wie ziet nu kans de waarde van een inboedel te bepalen als daarvan niet een eenigszins betrouwbare inventaris bestaat.

Zoolang de waarde van een dergelijk bezit zelfs niet bij benadering is vastgesteld, bestaat er steeds gevaar, dat concessiejagers beslag leggen op nationale schatten, ten voordeele van slechts enkelen, welke anders aangeboord het geheele land ten goede hadden kunnen komen.

Volslagen onbekendheid aangaande den aard en den omvang van de natuurlijke hulpbronnen van het land is wel de hoofdoorzaak, dat buitenlandsch kapitaal en buitenlandsche energie tot heden geen neiging aan den dag leggen iets in Suriname te ondernemen.

Hoe andere Zuid-Amerikaansche staten het aanleggen om kapitaal aan te lokken ter ontplooiing hunner schatten, kan blijken uit de jaarverslagen en consulaire rapporten dier landen. In dit opzicht valt er uit de economische geschiedenis van die republieken veel te leeren.

Ik heb hier met enkele trekken trachten aan te geven, waaraan het is toe te schrijven, dat Suriname tot nu toe een zoo groote economische starheid aan den dag legt, waarom de overgroote meerderheid der bevolking er zoo armelijk blijft, mij daarbij opzettelijk onthoudende van politiek en kritiek. Wanneer ik nu mijn wenschen voor den wederopbouw der wegkwijnende kolonie samenvat, beperken die zich vooreerst tot het naastvolgende: 
1. onderzoek naar cultures en daarmede verband houdende bedrijven geschikt om in Suriname te worden ingevoerd;

2. proefnemingen daarmede, teneinde na te gaan opwelke intensieve wijze die gedreven moeten worden om loonend te zijn voor den landbouw in het algemeen;

3. het invoeren van cultures en industrieën, waarvan op goeden grond te verwachten valt, dat die zullen bijdragen tot den economischen vooruitgang der kolonie; bevorderen door aanmoediging van het particulier initiatief;

4. stelselmatig onderzoek naar de natuurlijke hulpbronnen der kolonie, de waarde daarvan zoo goed mogelijk vaststellen en de resultaten van dit onderzoek, als die van positieven aard zijn, tegen betaling aan de koloniale kas van een behoorlijke vergoeding, ter beschikking stellen van aan hooge eischen voldoende gegadigden.

Voor een en ander is geld noodig, veel geld zelfs en het is haast niet denkbaar, dat het moederland onder de huidige tijdsomstandigheden, dat zal kunnen verschaffen boven en behalve het groote bedrag, dat het nu reeds jaarlijks aan de kolonie ten kostelegt. Dit laatste, wordt binnenkort tot afbetaling van kasvoorschotten besloten, zal met inbegrip der kosten voor de militaire bezetting als anderszins, weldra de 4 millioen 's jaars belangrijk overschrijden.

Dit ontstellend bedrag, ontstellend vooral, omdat het hier een kolonie betreft met slechts 115 duizend inwoners, doch ook, omdat het slechts dienen kan om daarginds de zaken min of meer gaande te houden, zal door de gelijkstelling van het onderwijs en de ondoordachte opvoering van het aantal pensioengerechtigde ambtenaren nog aanmerkelijk hooger worden, terwijl een noemenswaardige stijging der koloniale middelen vooreerst niet te verwachten is; daartoe is, inzonderheid na 1919, toen de prijzen van cacao en koffie een geruimen tijd voorbeeldeloos laag stonden, het economisch verval reeds te diep ingetreden.

De thans gevolgde financieele politiek ten opzichte van Suriname, het daar gaande houden der zaken, is op de keper 
beschouwd niet anders dan het bestendigen van misère voor moederland en kolonie en geen middel, dat daarin verbetering kan brengen, mag daarom onbeproefd blijven.

$\mathrm{Nu}$ komt het mij voor, dat op hoogergenoemd bedrag, hetwelk Nederland nu jaarlijks aan de kolonie ten koste legt, heel wat kan worden bezuinigd, en dat zoodoende toch nog fondsen gevonden kunnen worden voor den economischen opbouw van dat zoo in verval geraakte land.

Zoo is het mijne op kennis van toestanden gegronde overtuiging, dat de militaire bezetting in Suriname kan worden gemist. Voor het handhaven van inwendige rust en orde, haar eenige bestemming, is zij niet meer noodig, sedert de landbouw-ondernemingen er werken met uitsluitend Javanen, waarvan toch zeker geen ernstige rustverstoring is te verwachten. Die bezetting is dus van geen denkbaar nut meer, behoort derhalve te worden opgeheven, desnoods na eenige uitbreiding der politiemacht, wat op Hoofdstuk XI der staatsbegrooting zou leiden tot een bezuiniging van meer dan vijf ton.

Verder wil het mij voorkomen, dat het aantal pensioengerechtigde ambtenaren hetwelk in de laatste 3 jaren, op voorbeeld en met instemming van Nederland, van ruim 600 is opgevoerd tot 1100 en dat $70 \%$ van het budget verteert, gevoegelijk tot een meer bescheiden aantal kan worden teruggebracht. Die de koloniale administratie kent, weet, dat door reorganisatie en vereenvoudiging meerdere uitgaven tot een lager bedrag zouden zijn terug te brengen - en wat in zooveel groote maatschappijen uit geldelijken nooddwang plaats vindt, kan toch ook wel in Surniame toepassing vinden.

Bij het tot standbrengen van een inkrimping der uitgaven als hierbedoeld zal aanvankelijk niet teveel moeten worden verwacht van het daarover met het Koloniaal Bestuur te plegen overleg; het menschelijkerwijs gesproken zeer verklaarbaar eigenbelang ter plaatse zal zich daartegen verzetten, doch als de Regeering eens een enkelen keer wilde tewerkgaan als zooveel presidenten van Zuid-Amerikaansche republieken, die door krachtige, weleens eigenmachtige maatregelen, zooveel groots hebben tot stand 
gebracht, die hebben aangetoond, hoe landen welke nog in hun primitieve dagen verkeeren in korten tijd tot ontwikkeling zijn te brengen, dan zal beperking van vele in den grond onproductieve uitgaven voor Suriname zeer wel mogelijk blijken.

Trouwens wordt daar eenmaal ingezien, dat die beperking moet strekken tot opbouw der kolonie, dan zal die worden goedgekeurd, zelfs bevorderd.

Als Nederland nu de verschillende bedragen, welke op de staatsbegrooting voorkomen als uitgaven ten behoeve van de kolonie Suriname en welke spoedig hooger genoemd bedrag zullen beloopen en het karakter aannemen van een sneeuwbal, voor den tijd van b.v. 10 jaren, als vaste subsidie aan de kolonie zou willen toeleggen, onder beding evenwel, dat wat daarop zal kunnen worden uitgewonnen door reorganisatie, door inkrimping en opheffing van bemoeiingen, alsmede door versterking der middelen, zal dienen om een op te richten fonds te voeden, waaruit de kosten zullen worden bestreden voor den opbouw van het land, dan was het geld noodig voor krachtige hulp in uitersten nood, spoedig gevonden.

Door aanduiding met cijfers zou wellicht teveel persoonlijke aanwijzing worden gegeven; daarom blijft die hier achterwege, doch ik maak mij sterk te kunnen aantoonen, dat op de aangegeven wijze voor productief werk wel 7 ton 's jaars te vinden zouden zijn.

Tegen verwezenlijking van het hier ontwikkelde denkbeeld zijn misschien politieke en juridische bezwaren aan te voeren, welke ik niet voorzie, doch steekhoudende economische vermoedelijk niet, omdat het geen meerdere offers eischt van den Nederlandschen belastingbetaler, ook niet van den Surinaamschen en wel het meest voor de hand liggend middel is om eindelijk eens een nuttiger verhouding te scheppen tusschen de koloniale uitgaven eenerzijds en de daarmede te bereiken productieve einduitkomsten anderzijds, bovendien een krachtig middel kan worden tot opwekking der energie daarginds.

1 Mei 1923. 